\title{
Immunological analysis of the aqueous humour in candida endophthalmitis. II: Clinical study
}

\author{
A MATHIS,' F MALECAZE,' M H BESSIERES,' J L ARNE,' J P SEGUELA² \\ AND P BEC
}

From the 'Department of Ophthalmology, CHU Rangueil Toulouse, and 'Laboratory of Parasitology-Mycology, CHU Rangueil Toulouse, France

SUMMARY An anterior chamber paracentesis was carried out on six patients with candida endophthalmitis and on control subjects. We endeavoured to find out if there was local production of antibodies by evaluating the anti-candida antibody titres, the immunoglobulin $G$, and the albumin levels in the aqueous humour and in the serum. A significant difference in the level of specific antibodies between patients and controls was found. Local synthesis of anti-candida antibodies was discovered in five out of six patients with candida endophthalmitis. There would seem to be a correlation between the severity of uveitis and antibody titres.

Over the last two years the number of cases of candida endophthalmitis in Europe has increased, especially among heroin addicts. ${ }^{1}$ While the clinical ocular findings are quite typical, in order to be absolutely sure of the diagnosis it is necessary to recover the candida from the vitreous body. However, this procedure at times proves unsuccessful. We therefore carried out anterior paracentesis on six patients presenting symptoms of candida endophthalmitis to determine whether local production of antibodies was present in the aqueous humour.

\section{Materials and methods}

Patients. Our study was carried out by comparing two groups of subjects: patients with candida endophthalmitis and control patients.

The six patients with candida endophthalmitis are described below.

CASE 1

A 21-year-old woman, a drug addict, complained of blurred vision. Her visual acuity was finger counting at 3 feet $(1 \mathrm{~m})$ (OD and $O S)$. A dense cellular reaction was observed in the anterior chamber and in the vitreous. It was associated with a massive vitreous exudation in both eyes. The fundus examination, Correspondence to Dr F Malecaze, Service d'Ophtalmologie, CHU Toulouse Rangueil, Chemin du Vallon, 31054 Toulouse, France. difficult to perform, revealed in each eye a paramacular white mass extending into the vitreous. Blood cultures were negative. Candidosis serological results were: immunofluorescence 1:320; haemagglutination 1:20 480; immunoelectrophoresis against Candida albicans antigenic extract 6 precipitin lines. Scalp culture revealed Candida albicans colonies.

\section{CASE 2}

A 33-year-old man developed bilateral blindness following neurosurgery. Examination revealed severe anterior uveitis in both eyes as well as considerable vitreous organisation, making fundus examination impossible. Blood cultures were negative. Candidosis serological results were: immunofluorescence 1:80; haemagglutination 1:320; immunoelectrophoresis against Candida albicans antigenic extract 1 precipitin line.

CASE 3

A 28-year-old man, a drug addict, consulted us for decrease of visual acuity in the left eye. Ocular examination revealed left side visual acuity of $1 / 10$, severe anterior uveitis with many iris lens synechiae, and dense hyalitis obscuring retinal detail. The right eye was normal. Candidosis serological results were: immunofluorescence $1: 160$; haemagglutination 1:320; immunoelectrophoresis against Candida albicans antigenic extract 3 precipitin lines. Attempts to 
recover candida organisms from the blood and scalp were unsuccessful.

CASE 4

A 39-year-old man suffered from a candida septicaemia induced by intestinal perforation owing to sigmoid diverticulitis. The ocular symptoms developed one month later while he was convalescing. His visual acuity was obviously normal. The left eye had grade $1+$ cells in the anterior chamber and two exudative retinal lesions in the posterior pole. His right eye was normal on examination. Candidosis serological results were: immunofluorescence 1:320; haemagglutination 1:160; immunoelectrophoresis against Candida albicans antigenic extract 5 precipitin lines. Attempts to recover candida organisms from the blood and scalp were unsuccessful.

\section{CASE 5}

A 21-year-old man, a drug addict, presented with decreased visual acuity in the right eye. Ophthalmic examination revealed a visual acuity of $1 / 10$, a Tyndall light phenomenon in the anterior chamber $(1+$ cells $)$, a choroiditis paramacular lesion with local vitreous haze, and macular oedema. A search for candida from the scalp was negative. Candidosis serological results were: immunofluorescence 1:320; haemagglutination 1:20 480; immunoelectrophoresis against Candida albicans antigenic extract 2 precipitin lines. Blood cultures yielded many Candida albicans colonies.

\section{CASE 6}

A 30-year-old woman, a drug addict, had a visual acuity of $8 / 10$ in both eyes with a normal anterior segment. A fundus examination revealed two white, round, jutting paramacular lesions. Scalp culture yielded Candida albicans colonies. Blood cultures were negative. Candidosis serological results were: immunofluorescence 1:320; haemagglutination 1:160; immunoelectrophoresis against Candida albicans antigenic extract 2 precipitin lines.

The control group consisted of 14 patients (six males and eight females) undergoing routine cataract extraction or retinal detachment surgery. Their mean age was 42 years, range 24 to 72 years. All these patients had raised serum anti-candida antibody titres-above 80 by immunofluorescence, above 160 by haemagglutination, or at least 1 precipitin line in immunoelectrophoresis.

Methods. The same immunological studies were performed on the patients suffering from candida endophthalmitis as on the control group. In each patient in order to determine whether intraocular synthesis occurred it was necessary to evaluate the anti-candida antibody titre and the IgG level in the aqueous humour and in the serum. All the investigations were performed according to the methods described in the experimental study (anti-candida antibodies were analysed by indirect immunofluorescence according to Ambroise-Thomas'). Serum and aqueous humour albumin and immunoglobulin $G$ concentrations were analysed by laser immunonephelometry Behring). The only differences were: for immunofluorescence a goat antihuman immunoglobulin conjugated antibody (bioMérieux) was diluted to 1:100; for albumin analysis sera were diluted to 1:2000; aqueous humour was diluted to $1: 10$. For $\operatorname{IgG}$ analysis serum was diluted to $1: 200$, and aqueous humour was tested undiluted. In both cases concentrations were determined by comparison with dilutions of a standard human serum (standard protein Behring) analysed simultaneously under the same experimental conditions.

$C$ coefficient. As the presence of candida antibodies in the aqueous humour could be due either to a transudation of serum antibodies in the anterior chamber through the blood aqueous barrier, or to local synthesis, we calculated the $C$ coefficient as we did in the experimental candida endophthalmitis.

In interpreting the results we followed Desmonts' formula ${ }^{3}$ considering negative a $\mathrm{C}$ coefficient less than 2 , significant a $C$ from 2 to 4 , and positive a $C$ greater than 4 .

\section{Results}

The results of aqueous humour and serum samples obtained from patients with candida endophthalmitis are presented in Table 1. Anti-candida antibodies were found in the aqueous humour of five patients. Concentrations in all patients of albumin and immunoglobulin $\mathrm{G}$ were high in the aqueous humour. The $\mathrm{C}$ coefficient was positive in three cases, significant in two cases, and negative in one. In the patients with a positive coefficient there was very intense anterior segment inflammation. Two other patients with slight local production showed less serious anterior uveitis. The only patient with a normal anterior segment presented no local production of antibodies.

The results of immunological studies in the control group are presented in Table 2 . Despite raised anticandida antibody titres in the serum of each patient, specific antibodies were found in the aqueous humour in only seven patients. All cases showed a C coefficient equal to or less than 1.

\section{Discussion}

Clinical examination may make us fairly certain of 
Table 1 Results of tests on the aqueous humour and the serum: patients with candida endophthalmitis

\begin{tabular}{|c|c|c|c|c|c|c|c|}
\hline \multirow[t]{3}{*}{ Biological data } & \multicolumn{7}{|l|}{ Patients } \\
\hline & \multicolumn{2}{|l|}{$l$} & \multirow[t]{2}{*}{2} & \multirow[t]{2}{*}{3} & \multirow[t]{2}{*}{4} & \multirow[t]{2}{*}{5} & \multirow[t]{2}{*}{6} \\
\hline & Before cure & After cure & & & & & \\
\hline \multicolumn{8}{|l|}{ Immunoglobulin $\mathrm{G}$} \\
\hline Aqueous humour ( $\mathrm{mg} / \mathrm{l})$ & 410 & 25 & 68 & 240 & 50 & 24 & $12 \cdot 7$ \\
\hline Scrum $(\mathrm{mg} / \mathrm{l})$ & 18270 & 11510 & $93(0)$ & 12870 & 14800 & 16890 & 15050 \\
\hline \multicolumn{8}{|l|}{ Albumin } \\
\hline Aqueous humour ( $\mathrm{mg} / \mathrm{l})$ & 2050 & 220 & 206 & 1200 & 475 & 95 & 100 \\
\hline Serum $(\mathrm{mg} / \mathrm{l})$ & 32290 & 4() 22() & 36280 & 32610 & 41430 & $438(0)$ & 42900 \\
\hline \multicolumn{8}{|l|}{ Candida antibodies } \\
\hline Aqueous humour (titre) & 32 & No antibody & 8 & 20 & 2 & $\begin{array}{l}\text { Positive not } \\
\text { diluted }\end{array}$ & No antibody \\
\hline Serum (titre) & 320 & 80 & 80 & 160 & 320 & 320 & 320 \\
\hline C coefficient & $4 \cdot 5$ & $\begin{array}{l}\text { Nolocal } \\
\text { production }\end{array}$ & $13 \cdot 6$ & 7 & 2 & 2 & $\begin{array}{l}\text { No local } \\
\text { production }\end{array}$ \\
\hline
\end{tabular}

the presence of candida endophthalmitis. But confirmation depends on biological tests. However, recovering candida from an extraocular sample is by no means easy; in addition the interpretation of serological results causes some difficulty. In any case, neither a positive extraocular cultured site nor a serology suggesting recent visceral candidosis allows us to hold the candida organism responsible for the uveitis. Recovering candida organism from the eye is the only proof that candida infestation has actually occurred. Culture of aqueous humour ${ }^{+t h}$ has never revealed candida except in the case of an aphakic patient.' However, a vitreous $\operatorname{tap}^{\text {xy }}$ or a vitrectomy ${ }^{5111}$ does enable the collection of the candida organism. Recovering candida from the vitreous cavity is thus the best diagnostic method, though it may at times prove unsuccessful. In fact, vitreous tap is not always positive, ${ }^{1112}$ and vitrectomy may be negative despite concentration of the specimens, particularly after antifungal treatment. ${ }^{1+}$ Thus anterior chamber paracentesis, while presenting only presumptive diagnostic evidence, seems to be an interesting technique. Testing for production of intraocular specific antibodies by anterior chamber paracentesis can be used to diagnose uveitis caused by toxoplasmosis, ${ }^{3}$ herpes, ${ }^{13}$ and Toxocara canis. ${ }^{14}$ So far as we know it has never been used to confirm a diagnosis of candida endophthalmitis.

Immunological tests of the aqueous humour in candida endophthalmitis appear to be helpful. In fact numerous control studies have shown good reproducibility of these tests. Testing for local produc-

Table 2 Results of tests on the aqueous humour and the serum: control patients

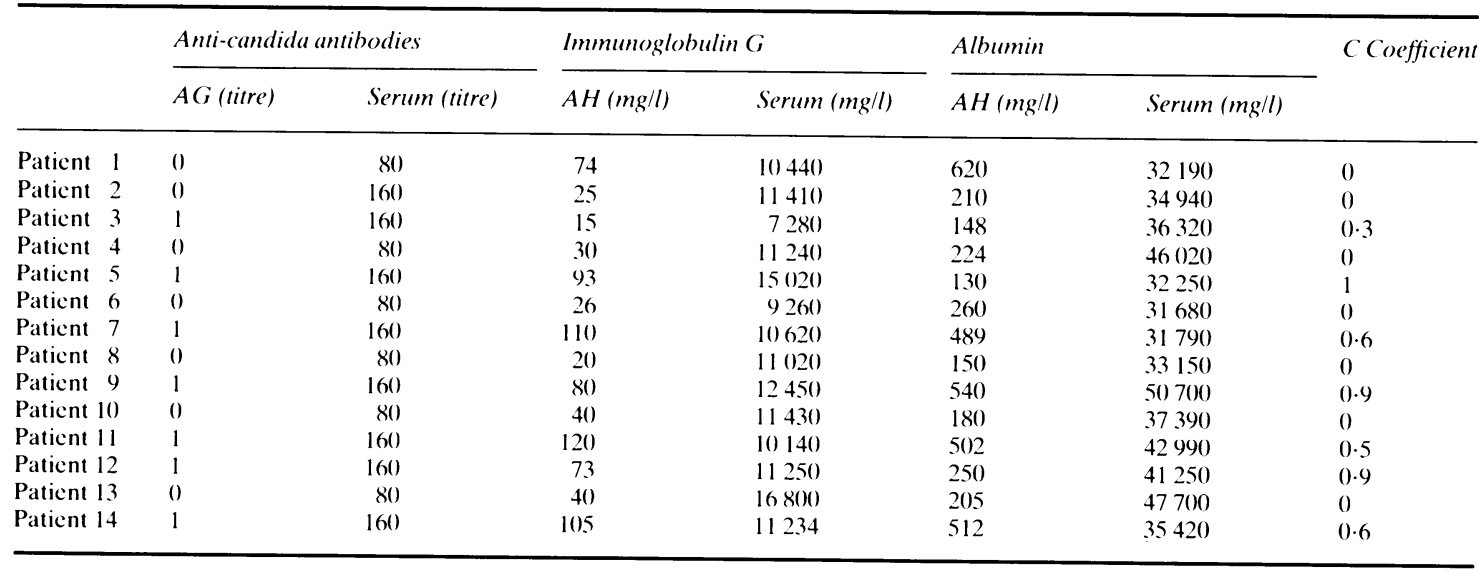

$\mathrm{AH}=$ aqueous humour . 
tion of anti-candida antibodies has enabled us to express strong support for the diagnosis of ocular candidosis in five out of six patients.

Moreover, it would seem to be justifiable to note that the more severe the anterior inflammation, the more revealing the anterior chamber paracentesis actually is. Testing for local production of anticandida antibodies has shown different immune responses: some of the results were significant, while others were only slightly positive or even negative. The last result may be explained either by a leak of specific serum antibodies through the blood-eye barrier which has been modified by inflammation, or by a tap performed too soon, as suggested by the results of our experimental study.

\section{References}

1 Sorrel TC, Dunlop C. Collignon PJ, Harding JA. Exogenous ocular candidosis associated with intravenous heroin abuse. $\mathrm{BrJ}$ Ophthalmol 1984; 68: 841-5.

2 Ambroise-Thomas P. Immunofluorescence indirecte. In: Golvan Y. Ambroise-Thomas P. eds. Nouvelles techniques en parasitologie. Paris: Flammarion, 1984: 181-4.

3 Desmonts G. Toxoplasmose oculaire. Etude épidémiologique. Bilan de 2030 examens d'humeur aqueuse. Arch Ophtalmol (Paris) 1973: 83: 87-102.
4 Barthelemy F. Offret H. Saragoussi JJ, Pouliquen Y, Dhermy P. Toxicomanies et endophtalmies à Candida albicans: problèmes diagnostiques et thérapeutiques. J Fr Ophtalmol 1981; 4: 637-46.

5 Elliot JH. O'Day DM. Gutow GS. Podgorski SF, Akrabawi P. Mycotic endophthalmitis in drug abusers. Am J Ophthalmol 1979; 88: 66-72.

$6 \mathrm{O}^{\circ}$ Connor GR. Uveitis and the immunologically compromised host. N Engl J Med 1978; 299: 130-2

7 Robertson DM, Ricley FC. Hermans PE. Endogenous candida oculomycosis. Arch Ophthalmol 1974: 91: 33-8.

8 Forster RK, Zachary IG, Cottingham AJ, Norton WD. Further observations on the diagnosis, cause, and treatment of endophthalmitis. Am J Ophthalmol 1976: 81: 52-6.

9 Rowsey JJ. Newsom DL. Sexton DJ, Harms WK. Endophthalmitis: current approaches. Ophthalmology 1982; 89: 1055-66.

10) Aguilar GL, Blumenkrantz MS, Egbert PR, McCulley JP Candida endophthalmitis after intravenous drug abuse. Arch Ophthalmol 1979; 97: 96-100.

11 Snip RC. Michels RG. Pars plana vitrectomy in the management of endogenous endophthalmitis. Am J Ophthalmol 1976; 82: 699-7()4.

12 Le Rebeller MJ, Lagoutte F. Dupuy P. Endophtalmic à Candida albicans chez les herönomanes. Bull Soc Fr Ophtalmol 1981; 11: 917-22.

13 Denis J, Rossignol A, Langlois M, Dorey C, Aymard M, Giraud JP. Valeur du coefficient de charge immunitaire des globulines de l'humeur aqueuse au cours de l'herpès oculaire. J Fr Ophtalmol 1981:4: 173.

14 Felberg NT. Shields JA. Federman JL. Antibody to Toxocara canis in the aqueous humor. Arch Ophthalmol 1981; 99: 1563-4.

Accepted for publication 29 January 1987. 